\title{
BMJ
}

\section{New evidence on the impact of China's New Rural Cooperative Medical Scheme and its implications for rural primary healthcare: multivariate difference-in-difference analysis}

\section{Kimberly Singer Babiarz, PhD candidate, ${ }^{1}$ Grant Miller, assistant professor, ${ }^{2}$ Hongmei Yi, postdoctoral fellow, ${ }^{3}$ Linxiu Zhang, deputy director, ${ }^{3}$ Scott Rozelle, senior research fellow ${ }^{4}$}

Department of Agricultural and Resource Economics, University of California, Davis, USA

${ }^{2}$ Stanford Medical School and National Bureau of Economic Research, Stanford, USA

${ }^{3}$ Center for Chinese Agricultural Policy, Institute of Geographical Sciences and Natural Resources Research, Chinese Academy of Sciences, Beijing, China

${ }^{4}$ Freeman Spogli Institute for International Studies, Stanford University, Stanford, USA

Correspondence to: $\mathrm{G}$ Miller ngmiller@stanford.edu

Cite this as: $B M J$ 2010;341:c5617 doi:10.1136/bmi.c5617

\section{ABSTRACT}

Objectives To determine whether China's New Rural Cooperative Medical Scheme (NCMS), which aims to provide health insurance to 800 million rural citizens and to correct distortions in rural primary care, and the individual policy attributes have affected the operation and use of village health clinics.

Design We performed a difference-in-difference analysis using multivariate linear regressions, controlling for clinic and individual attributes as well as village and year effects. Setting 100 villages within 25 rural counties across five Chinese provinces in 2004 and 2007.

Participants 160 village primary care clinics and 8339 individuals.

Main outcome measures Clinic outcomes were log average weekly patient flow, log average monthly gross income, log total annual net income, and the proportion of monthly gross income from medicine sales. Individual outcomes were probability of seeking medical care, log annual "out of pocket" health expenditure, and two measures of exposure to financial risk (probability of incurring out of pocket health expenditure above the 90th percentile of spending among the uninsured and probability of financing medical care by borrowing or selling assets).

Results For village clinics, we found that NCMS was associated with a $26 \%$ increase in weekly patient flow and a $29 \%$ increase in monthly gross income, but no change in annual net revenue or the proportion of monthly income from drug revenue. For individuals, participation in NCMS was associated with a $5 \%$ increase in village clinic use, but no change in overall medical care use. Also, out of pocket medical spending fell by $19 \%$ and the two measures of exposure to financial risk declined by $24-63 \%$. These changes occurred across heterogeneous county programmes, even in those with minimal benefit packages. Conclusions NCMS provides some financial risk protection for individuals in rural China and has partly corrected distortions in Chinese rural healthcare (reducing the oversupply of specialty services and prescription drugs). However, the scheme may have also shifted uncompensated new responsibilities to village clinics. Given renewed interest among Chinese policy makers in strengthening primary care, the effect of NCMS deserves greater attention.

\section{INTRODUCTION}

After the end of China's Maoist period in 1976, a series of market based economic reforms were introduced that resulted in unprecedented social and economic gains. However, because state support for public health insurance and delivery of health services in rural areas was tied to collectivised agricultural organisations (that is, communes, which were disbanded during the late 1970s and early 1980s), an unintended consequence of economic decollectivisation was the near collapse of China's rural health system. ${ }^{12}$ Fiscal decentralisation during the 1980s and 1990s further undercut the rural health system's public finance base, ${ }^{1}$ and central government health funds were increasingly focused on wealthy urban areas. ${ }^{3}$ Consequently, 640 million people in rural China effectively became uninsured, ${ }^{4-6}$ and hundreds of thousands of rural health facilities amassed large operating deficits. These financial shortfalls led village clinicians (known as "barefoot doctors") to open private clinics en masse, while public sector health facilities raised prices. ${ }^{1}$ In addition, government regulatory responses made specialty medical care and drug prescription relatively more lucrative, which prompted doctors to overprescribe these services. ${ }^{711}$ The overall result was an escalation of spending on medical services and an increase in household exposure to financial risk. ${ }^{12-14}$

Before the reforms, China had a three tier rural health system supported entirely by state funding. At the village level, hundreds of thousands of barefoot doctors formed the base of the system's provision of primary healthcare. Practising both Western and Chinese medicine, they provided basic outpatient services, offered emergency first aid, delivered immunisations, and conducted public health surveillance. These community based clinicians were the entry point into the health system, and they referred cases that they could not treat to higher level health facilities. Township 
health centres were the system's second tier. Located in township centres and staffed by formally trained doctors and nurses, these centres provided inpatient services and treated more complicated outpatient conditions. Larger county (or district) hospitals were the third tier. Located in county seats far away from many villages, these hospitals were staffed by rural China's best trained doctors. They provided the system's most specialised inpatient and outpatient medical care. This tiered structure survived the market based reforms of the 1980s.

In 2003, China, recognising the growing rural healthcare crisis created by de-collectivisation, established one of the largest public sector health insurance programmes in the world: the New Rural Cooperative Medical Scheme (NCMS). ${ }^{124}$ At the time of our survey, households could purchase health insurance for modest premiums of 10 to 20 Yuan (roughly $\$ 1.50$ to $\$ 3.00$ (£0.94 to $£ 1.89 ; € 1.08$ to $€ 2.15)$ ) per person. Local and central governments each contributed subsidies of 20 to 40 Yuan per enrolled individual. Within five years, $\mathrm{NCMS}$ had expanded to include 800 million people in rural China. ${ }^{1516}$

NCMS is administered at the county level, so coverage has varied across regions of China and over time. Although all county programmes cover at least a portion of inpatient expenses, county administrators are encouraged to define benefits packages on the basis of local needs and resources. Local health officials establish reimbursement levels, designate participating

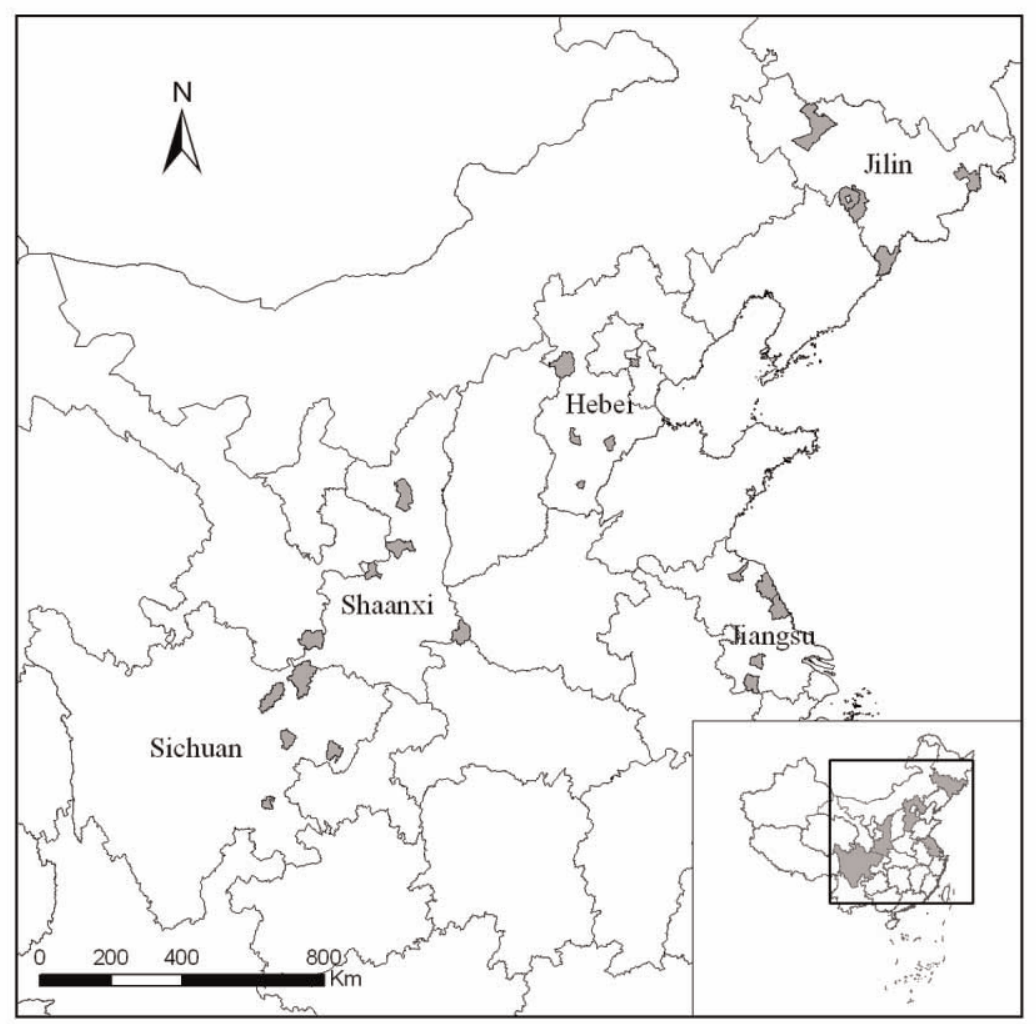

Location of the counties sampled in the provinces of Jiangsu, Sichuan, Shaanxi, Jilin, and Hebei providers, pool risk across local subscribers, and experiment with a variety of policy innovations. This local decision making has created substantial differences in coverage between counties. By 2007, many counties had expanded benefits beyond inpatient reimbursement to include outpatient services at hospitals, township health centres, and village clinics. Other counties required households to invest in compulsory medical savings accounts (hereafter "household accounts"). These accounts are often used for outpatient services at village clinics and account balances are carried over to the next year if not used in full.

Village clinics constitute the primary care and public health service backbone of rural China. Taken together, clinics serve many more patients than local township health centres, and they often are the only reasonable source of medical care in China's most remote villages. Given the central role of village clinics in the delivery of rural healthcare and reform efforts to promote primary care over specialty care, it is essential to understand how NCMS is affecting clinic operations and viability. We evaluated the effect of NCMS on individuals and village clinics by using individual level and village clinic level data collected in 2004 (shortly after the introduction of the scheme in selected regions) and in 2007 (after the dramatic expansion of the scheme across most rural areas) from 100 villages in 25 rural counties of five provinces in China.

\section{METHODS \\ Data}

We used two waves of a data set collected by the Chinese Academy of Sciences' Centre for Chinese Agriculture Policy in collaboration with Stanford University, CA, USA. The data set contains three major components: a village clinic module; a household module; and a county module. The first wave was conducted in April 2005, when data from 2004 was collected in a random sample of 100 villages from 25 rural counties in the Chinese provinces of Jiangsu, Sichuan, Shaanxi, Jilin, and Hebei. Sample counties are illustrated in figure 1. The resulting sample included 156 village clinics and 3257 individuals. The second wave sampled the same 100 villages in April 2008, collecting 2007 data from 160 clinics and 8339 individuals. In the first wave, eight households in each village were randomly drawn and surveyed; in the second wave, the sample was increased to 20 households in each village (the original eight plus twelve additional randomly selected households). The survey instrument used in the second round was an expanded version of the instrument used in the first round. Our analyses used variables collected in both waves.

To ensure that our sample was nationally representative, we randomly sampled one province from each of China's five major agro-ecological zones: Shaanxi province in the arid north west; Sichuan province in the poor, mountainous south west; Jiangsu province in the low lying south eastern coastal region; Hebei province in the flat northern plains region; and Jilin province in the far north east temperate region. We then drew five 
Table 1|Descriptive statistics for the New Rural Cooperative Medical Scheme (NCMS): policy attributes; village clinic outcomes; and individual outcomes

\begin{tabular}{|c|c|c|c|c|c|c|}
\hline & \multicolumn{2}{|c|}{ Overall } & \multicolumn{2}{|c|}{ NCMS } & \multicolumn{2}{|c|}{ No NCMS } \\
\hline & 2004 & 2007 & 2004 & 2007 & 2004 & 2007 \\
\hline \multicolumn{7}{|l|}{ Policy attributes } \\
\hline Proportion of villages with NCMS programmes & $24 \%(24 / 100)$ & $100 \%(100 / 100)$ & - & - & - & - \\
\hline Total number of individuals enrolled in NCMS & 620 & 7450 & - & - & - & - \\
\hline Proportion of sample enrolled in NCMS & $19 \%(620 / 3257)$ & $89 \%(7450 / 8339)$ & - & - & - & - \\
\hline $\begin{array}{l}\text { Proportion of villages with at least one clinic that } \\
\text { provided reimbursement }\end{array}$ & $16 \%(16 / 100)$ & $49 \%(49 / 100)$ & - & - & - & - \\
\hline $\begin{array}{l}\text { Proportion of clinics designated for } \\
\text { reimbursement }\end{array}$ & $10 \%(17 / 156)$ & $40 \%(64 / 160)$ & - & - & - & - \\
\hline $\begin{array}{l}\text { Proportion of local programmes with outpatient } \\
\text { reimbursement }\end{array}$ & $50 \%(12 / 24)$ & $48 \%(48 / 100)$ & - & - & - & - \\
\hline $\begin{array}{l}\text { Proportion of local programmes with household } \\
\text { medical savings accounts }\end{array}$ & $42 \%(10 / 24)$ & $64 \%(64 / 100)$ & - & - & - & - \\
\hline \multicolumn{7}{|l|}{ Village clinic outcomes } \\
\hline $\mathrm{N}$ & 156 & 160 & 17 & 64 & 139 & 96 \\
\hline Average (SD) weekly patient flow & $52(47)$ & $53(55)$ & $95(57)$ & $49(40)$ & $47(44)$ & $56(63)$ \\
\hline Average (SD) monthly gross income (Yuan) & $2489(2870)$ & $3212(4821)$ & $5625(4395)$ & 2379 (1892) & $2117(2397)$ & $3772(5991)$ \\
\hline $\begin{array}{l}\text { Average (SD) share of monthly gross income from } \\
\text { medicine sales }\end{array}$ & $87 \%(0.43)$ & $83 \%(0.18)$ & $79 \%(0.16)$ & $82 \%(0.18)$ & $87 \%(0.45)$ & $83 \%(0.18)$ \\
\hline Average (SD) annual net income (Yuan) & $10941(19347)$ & $11362(18885)$ & $17500(13473)$ & $8461(6816)$ & $10345(19725)$ & $13307(23617)$ \\
\hline \multicolumn{7}{|l|}{ Individual outcomes } \\
\hline $\mathrm{N}$ & 3257 & 8339 & 620 & 7450 & 2637 & 889 \\
\hline Proportion of individuals reporting illness & $75 \%(2411 / 3211)$ & $59 \%(4769 / 8019)$ & $75 \%(460 / 617)$ & $61 \%(4424 / 7239)$ & $75 \%(1947 / 2588)$ & $44 \%(345 / 780)$ \\
\hline $\begin{array}{l}\text { Proportion of sick individuals seeking medical } \\
\text { care }\end{array}$ & $91 \%(2180 / 2407)$ & $95 \%(4516 / 4756)$ & $86 \%(397 / 460)$ & $95 \%(4201 / 4415)$ & $91 \%(1781 / 1943)$ & $92 \%(315 / 341)$ \\
\hline $\begin{array}{l}\text { Proportion of sick individuals seeking medical } \\
\text { care at township health centres or hospitals }\end{array}$ & $35 \%(760 / 2138)$ & $46 \%(1971 / 4262)$ & $34 \%(133 / 396)$ & $45 \%(1809 / 3972)$ & $36 \%(625 / 1740)$ & $56 \%(162 / 290)$ \\
\hline $\begin{array}{l}\text { Average (SD) annual out of pocket health } \\
\text { expenditure (Yuan) }\end{array}$ & 801 (2559) & $1106(3338)$ & $624(1624)$ & $1110(3417)$ & $842(2728)$ & $1038(2011)$ \\
\hline $\begin{array}{l}\text { Proportion of individuals incurring out of pocket } \\
\text { health expenditure in the 90th percentile of } \\
\text { spending among uninsured }\end{array}$ & $7 \%(175 / 2411)$ & $7 \%(328 / 4771)$ & $7 \%(32 / 460)$ & $7 \%(299 / 4426)$ & $7 \%(143 / 1947)$ & $8 \%(29 / 345)$ \\
\hline $\begin{array}{l}\text { Proportion of individuals financing healthcare } \\
\text { through asset sales or borrowing }\end{array}$ & $6 \%(119 / 2134)$ & $4 \%(165 / 4517)$ & $2 \%(8 / 396)$ & $4 \%(151 / 4202)$ & $6 \%(111 / 1736)$ & $4 \%(14 / 315)$ \\
\hline
\end{tabular}

sample counties from each province by using a two step procedure. Firstly, the enumeration team listed all counties in each province in descending order according to gross value of industrial output per capita. This measure is a better predictor of living standards and development potential than rural income per capita. ${ }^{17}$ Secondly, five sample counties were selected randomly from each province list - one from each quintile of gross value of industrial output. We then randomly selected towns (two from each county-one from the top and one from bottom half of the distribution) and villages (two from each town) from these counties using the same two step sampling procedure.

The village clinic module collected information about clinic use, finances, and operations. Specific variables were average weekly patient flow, average monthly gross income, total net annual income, and the proportion of monthly income attributable to medicine sales. To ensure high quality data, survey teams cross validated income and expense measures during interviews and reconciled discrepancies as necessary. Clinics also provided information about participation in NCMS and programme rules, including whether or not patient expenditures were reimbursable. Clinicians were also asked questions about work related to the scheme performed throughout the year and how they felt that the scheme had affected their business.

The household (individual) module gathered detailed information about spending on medical care and use of health services in the past year for each family member. Household heads in every sample household completed the surveys. Information about other household members was collected as well- - either from these individuals themselves (if present) or from household heads and spouses (if absent). Specific variables were whether a household participated in NCMS, whether each individual was ill during the past year, whether each person who was sick consulted a doctor, and the type of facility from which medical care was received (village clinic, township health centre, county hospital, or provincial hospital). Respondents were also asked how much was spent on healthcare and how medical care was financed (for example, how much was spent "out of pocket," how much was reimbursed by NCMS, and how much was financed by borrowing or selling assets). For out of pocket spending, respondents were instructed to report only expenses paid for clinical services and drugs (not spending on transportation and meals, for example). 
Table 2 | Impact of the New Rural Cooperative Medical Scheme (NCMS) on village clinic level outcomes: basic model

\begin{tabular}{|c|c|c|c|c|}
\hline & $\begin{array}{l}\text { Log average weekly } \\
\text { patient flow }\end{array}$ & $\begin{array}{l}\text { Log average monthly } \\
\text { gross income }\end{array}$ & $\begin{array}{l}\text { Proportion of monthly gross } \\
\text { income from medicine sales }\end{array}$ & $\begin{array}{l}\text { Log total annual net } \\
\text { income }\end{array}$ \\
\hline $\begin{array}{l}\text { Clinic eligibility for reimbursement } \\
\text { through NCMS }\end{array}$ & $0.26^{*}(-0.02$ to 0.54$)$ & $0.29^{\star \star}(0.02$ to 0.55$)$ & $-0.02(-0.17$ to 0.12$)$ & $0.09(-0.16$ to 0.34$)$ \\
\hline 2007 & $-0.27^{\star}(-0.60$ to 0.05$)$ & $0.06(-0.18$ to 0.31$)$ & $-0.02(-0.13$ to 0.09$)$ & 0.11 (-0.06 to 0.28$)$ \\
\hline Observations & 301 & 301 & 298 & 291 \\
\hline R squared & 0.64 & 0.71 & 0.31 & 0.78 \\
\hline
\end{tabular}

Point estimates for natural log transformed dependent variables can roughly be interpreted as percent changes (or relative changes); estimates from linear probability models can be interpreted as percentage point changes (or absolute changes). $95 \%$ confidence intervals are reported in parentheses.

Linear probability models include full set of village and year fixed effects, and control for number of doctors, doctor training, doctor age, size of service area, size of medicine stock, and average village income per capita.

${ }^{*} \mathrm{P}<0.10 ;{ }^{* *} \mathrm{P}<0.05 ;{ }^{* * * P} \mathrm{P}<0.01$.

Finally, the county module (executed in each of the 25 counties; five counties per province) collected data on the features of NCMS programmes in each county from local scheme officials and township health centres. These scheme attributes included the types of services that qualified for reimbursement (inpatient only or inpatient and outpatient) and whether programmes included household accounts. Descriptive statistics for these data are provided in table 1 .

\section{Statistical analysis}

Our analyses of how village clinic operations and individual welfare have changed under NCMS took three basic forms. For simplicity, we call these the basic, full, and combined models. We used ordinary least squares regression to analyse both clinic level and individual level data in each model. We accounted for the clustered nature of our sample in all analyses by constructing Huber-White standard errors corrected for village level clustering (relaxing the assumption that disturbance terms are independent and identically distributed within villages).

Our four key outcome variables at the village clinic level were average weekly patient flow, average monthly gross income, proportion of monthly gross income from medicine sales, and total annual net income. Our main individual level outcomes were whether an individual sought medical care conditional on being sick, whether medical care was sought at a township health centre or hospital, total annual out of pocket health expenditure, and measures of exposure to financial risk (that is, whether out of pocket spending exceeded the 90th percentile of spending among the uninsured and whether medical care was financed by borrowing or selling assets).

The basic model estimated how village clinic and individual outcomes were associated with a single NCMS treatment measure (controlling for a detailed set of clinic and individual characteristics, respectively). For clinics, this variable was eligibility for scheme reimbursement, whereas for individuals it was participation in the scheme. At the village clinic level, we controlled for the number of doctors, doctor training, doctor age, size of service area, size of medicine stock, and average village income per capita. In the individual level models, we controlled for gender, age, the square of age, education, urban or rural resident status, and mean per capita village income. Finally, to adjust for unobserved differences across villages (including those that stem from geographic inequities) and to account for common changes over time, we also included dummy variables for villages and years (in our case, for the year 2007).

Given the substantial cross county heterogeneity in NCMS policies, the full model then estimated how village clinic and individual outcomes were associated with distinct policy attributes of county programmes (hereafter "policy attributes") in addition to the single treatment measure. Results from the full model provide a more nuanced picture of specific mechanisms embedded in the scheme that might explain its effect. The three specific policy attributes that we analysed for clinics were availability of the scheme to village residents, coverage

Table 3| Impact of the New Rural Cooperative Medical Scheme (NCMS) on individual level outcomes: basic model

\begin{tabular}{|c|c|c|c|c|c|}
\hline & $\begin{array}{l}\text { Probability of seeking } \\
\text { medical care }\end{array}$ & $\begin{array}{l}\text { Probability of seeking medical } \\
\text { care at township health centre or } \\
\text { larger hospital }\end{array}$ & $\begin{array}{l}\text { Log annual out of pocket } \\
\text { health expenditure }\end{array}$ & $\begin{array}{l}\text { Probability of incurring out of } \\
\text { pocket health expenditure in the } \\
\text { 90th percentile of spending } \\
\text { among uninsured }\end{array}$ & $\begin{array}{l}\text { Probability of financing } \\
\text { healthcare through asset } \\
\text { sales or borrowing }\end{array}$ \\
\hline Enrolment in NCMS & $0.01(-0.03$ to 0.04$)$ & $-0.05^{\star}(-0.11$ to 0.00$)$ & $-0.19^{\star *}(-0.36$ to -0.02$)$ & $-0.02^{\star}(-0.04$ to 0.00$)$ & $-0.02^{*}(-0.05$ to 0.00$)$ \\
\hline 2007 & 0.02 (0.01 to 0.02$)$ & $0.13^{\star \star \star}(0.07$ to 0.19$)$ & $0.49^{\star \star \star}(0.25$ to 0.72$)$ & $0.02(-0.01$ to 0.04$)$ & $-0.02(-0.06$ to 0.02$)$ \\
\hline Observations & 6780 & 6487 & 6201 & 6797 & 6304 \\
\hline R squared & 0.07 & 0.11 & 0.11 & 0.01 & 0.07 \\
\hline
\end{tabular}

Point estimates for natural log transformed dependent variables can roughly be interpreted as percent changes (or relative changes); estimates from linear probability models can be

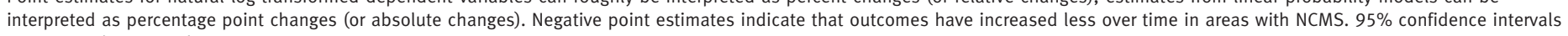
are reported in parentheses.

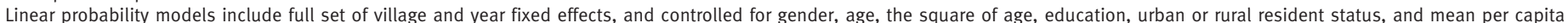
village income.

${ }^{\star} \mathrm{P}<0.10$; ${ }^{* *} \mathrm{P}<0.05 ;{ }^{* \star *} \mathrm{P}<0.01$. 
Table 4 | Impact of the New Rural Cooperative Medical Scheme (NCMS) on village clinic level outcomes: full model

\begin{tabular}{|c|c|c|c|c|}
\hline & $\begin{array}{l}\text { Log average weekly } \\
\text { patient flow }\end{array}$ & $\begin{array}{l}\text { Log average monthly } \\
\text { gross income }\end{array}$ & $\begin{array}{l}\text { Proportion of monthly gross } \\
\text { income from medicine sales }\end{array}$ & $\begin{array}{l}\text { Log total annual } \\
\text { net income }\end{array}$ \\
\hline \multicolumn{5}{|l|}{ Clinic level } \\
\hline Clinic eligibility for reimbursement through NCMS & $0.22(-0.08$ to 0.53$)$ & $0.18(-0.16$ to 0.52$)$ & $0.06(-0.11$ to 0.23$)$ & $0.12(-0.17$ to 0.42$)$ \\
\hline \multicolumn{5}{|l|}{ Village level } \\
\hline Clinic in a village with NCMS & $0.55^{*}(-0.01$ to 1.11$)$ & $0.71^{\star \star \star}(0.20$ to 1.20$)$ & $-0.25(-0.66$ to 0.17$)$ & $-0.25(-0.58$ to 0.09$)$ \\
\hline \multicolumn{5}{|l|}{ County level } \\
\hline $\begin{array}{l}\text { Outpatient reimbursement available at township health } \\
\text { centre }\end{array}$ & $0.28(-0.06$ to 0.63$)$ & $-0.06(-0.38$ to 0.27$)$ & $0.02(-0.14$ to 0.18$)$ & $0.04(-0.22$ to 0.31$)$ \\
\hline Household medical savings account requirement & $-0.39 * \star(-0.71$ to -0.06$)$ & $-0.33(-0.80$ to 0.14$)$ & $-0.05(-0.38$ to 0.28$)$ & $0.13(-0.18$ to 0.45$)$ \\
\hline 2007 & $-0.53^{*}(-1.10$ to 0.03$)$ & $-0.27(-0.64$ to 0.10$)$ & $0.19 *(-0.01$ to 0.38$)$ & $0.21(-0.13$ to 0.55$)$ \\
\hline Observations & 301 & 301 & 298 & 291 \\
\hline R squared & 0.66 & 0.72 & 0.32 & 0.78 \\
\hline \multicolumn{5}{|c|}{$\begin{array}{l}\text { Point estimates for natural log transformed dependent variables can roughly be interpreted as percent changes (or relative changes); estimates from linear probability models can be } \\
\text { interpreted as percentage point changes (or absolute changes). Negative point estimates indicate that outcomes have increased less over time in the areas with NCMS or relevant policy } \\
\text { attributes. } 95 \% \text { confidence intervals are reported in parentheses. } \\
\text { Linear probability models include full set of village and year fixed effects, and control for number of doctors, doctor training, doctor age, size of service area, size of medicine stock, and } \\
\text { average village income per capita. } \\
{ }^{\star} P<0.10 ;{ }^{\star \star P}<0.05 ;{ }^{\star \star \star P}<0.01 \text {. }\end{array}$} \\
\hline
\end{tabular}

of outpatient services at local township health centres, and household account requirements. The policy attributes that we studied for individuals were the availability of reimbursement for village clinic services, the availability of reimbursement for outpatient services at township health centres and hospitals, and whether or not an individual's family had a household account. All control variables included in the basic models were also incorporated into the full models.

Finally, to evaluate the combined impact of common county level bundles of policy features, we specified three frequently observed bundles of policy features (hereafter "policy bundles"): (A) reimbursement for inpatient services at township health centres and hospitals from the common fund; (B) reimbursement for inpatient services at township health centres and hospitals from the common fund plus reimbursement for village clinic services from household accounts; and (C) reimbursement for inpatient and outpatient services at township health centres and hospitals from the common fund plus reimbursement for village clinic services from household accounts. In other words, (B) $=(\mathrm{A})+$ clinic reimbursement from household accounts, and $(\mathrm{C})=(\mathrm{B})+$ reimbursement for outpatient services. These policy bundles were intended to group similar policies for purposes of analysis, not to unambiguously order policies from more to less generous (or "better" to "worse"). To calculate the effect of each policy bundle on village clinic and individual outcomes, we used the full model to conduct joint significance tests of each bundle's components. When justified by significant F statistics, we then summed across policy components to obtain the implied net effect of each of the three combinations.

Table 5 | Impact of the New Rural Cooperative Medical Scheme (NCMS) on individual level outcomes: full model

\begin{tabular}{|c|c|c|c|c|c|}
\hline & $\begin{array}{l}\text { Probability of seeking } \\
\text { medical care }\end{array}$ & $\begin{array}{l}\text { Probability of seeking } \\
\text { medical care at } \\
\text { township health centre } \\
\text { or larger hospital }\end{array}$ & $\begin{array}{l}\text { Log annual out of } \\
\text { pocket health } \\
\text { expenditure }\end{array}$ & $\begin{array}{l}\text { Probability of incurring } \\
\text { out of pocket health } \\
\text { expenditure in the 90th } \\
\text { percentile of spending } \\
\text { among uninsured }\end{array}$ & $\begin{array}{l}\text { Probability of financing } \\
\text { healthcare through } \\
\text { asset sales or borrowing }\end{array}$ \\
\hline \multicolumn{6}{|l|}{ Individual level } \\
\hline Enrolment in NCMS & $-0.01(-0.08$ to 0.05$)$ & $-0.01(-0.11$ to 0.09$)$ & $0.02(-0.23$ to 0.28$)$ & $-0.01(-0.04$ to 0.02$)$ & $-0.03(-0.09$ to 0.02$)$ \\
\hline \multicolumn{6}{|l|}{ Village level } \\
\hline Reimbursement available at village clinic & $-0.01(-0.05$ to 0.05$)$ & $-0.05(-0.11$ to 0.01$)$ & $-0.03(-0.22$ to 0.16$)$ & $0.01(-0.02$ to 0.03$)$ & $-0.03^{*}(-0.05$ to 0.00$)$ \\
\hline \multicolumn{6}{|l|}{ County level } \\
\hline $\begin{array}{l}\text { Outpatient reimbursement available at township } \\
\text { health centre }\end{array}$ & $0.04(-0.01$ to 0.10$)$ & $-0.01(-0.09$ to 0.06$)$ & $-0.19^{\star}(-0.39$ to 0.01$)$ & $-0.01(-0.03$ to 0.01$)$ & $0.03(-0.01$ to 0.06$)$ \\
\hline Household medical savings account requirement & $0.01(-0.04$ to 0.06$)$ & $0.01(-0.09$ to 0.08$)$ & $-0.20^{\star}(-0.42$ to 0.02$)$ & $-0.02(-0.04$ to 0.01$)$ & $0.02(-0.01$ to 0.06$)$ \\
\hline 2007 & $0.01(-0.03$ to 0.05$)$ & $0.12^{\star \star \star}(0.05$ to 0.18$)$ & $0.50^{\star \star \star}(0.27$ to 0.71$)$ & $0.02^{\star}(-0.00$ to 0.05$)$ & $-0.03(-0.07$ to 0.01$)$ \\
\hline Observations & 6692 & 6400 & 6132 & 6709 & 6061 \\
\hline R squared & 0.08 & 0.11 & 0.09 & 0.01 & 0.07 \\
\hline
\end{tabular}

Point estimates for natural log transformed dependent variables can roughly be interpreted as percent changes (or relative changes); estimates from linear probability models can be interpreted as percentage point changes (or absolute changes). Negative point estimates indicate that outcomes have increased less over time in areas with NCMS or relevant policy attributes. 95\% confidence intervals are reported in parentheses.

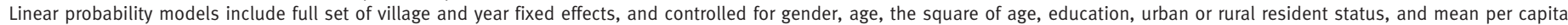
village income.

${ }^{*} \mathrm{P}<0.10 ;{ }^{* \star} \mathrm{P}<0.05 ;{ }^{* \star *} \mathrm{P}<0.01$. 
Table 6| Impact of the New Rural Cooperative Medical Scheme on village clinic level outcomes: combined model

\begin{tabular}{|c|c|c|c|c|}
\hline & $\begin{array}{l}\text { Log average weekly } \\
\text { patient flow }\end{array}$ & $\begin{array}{l}\text { Log average } \\
\text { monthly } \\
\text { gross income }\end{array}$ & $\begin{array}{l}\text { Proportion of monthly } \\
\text { gross income from } \\
\text { medicine sales }\end{array}$ & $\begin{array}{l}\text { Log total annual } \\
\text { net income }\end{array}$ \\
\hline \multicolumn{5}{|l|}{ Policy bundle A } \\
\hline $\begin{array}{l}\text { Reimbursement for inpatient services at township health centres and hospitals from the } \\
\text { common fund }\end{array}$ & $0.55^{\star \star}(0.05)$ & $0.71^{\star \star \star}(0.01)$ & $-0.25(0.24)$ & $-0.25(0.15)$ \\
\hline \multicolumn{5}{|l|}{ Policy bundle B } \\
\hline $\begin{array}{l}\text { Reimbursement for inpatient services at township health centres and hospitals from the } \\
\text { common fund plus reimbursement for village clinic services from household accounts }\end{array}$ & $0.38^{\star * \star}(0.01)$ & $0.38^{\star \star \star}(0.00)$ & $-0.24^{\star \star \star}(0.01)$ & $0.00(0.40)$ \\
\hline \multicolumn{5}{|l|}{ Policy bundle C } \\
\hline $\begin{array}{l}\text { Reimbursement for inpatient and outpatient services at township health centres and } \\
\text { hospitals from the common fund plus reimbursement for village clinic services from } \\
\text { household accounts }\end{array}$ & $0.66^{\star \star \star}(0.00)$ & $0.56^{\star \star \star}(0.00)$ & $-0.22^{\star \star}(0.02)$ & $0.04(0.55)$ \\
\hline \multicolumn{5}{|c|}{$\begin{array}{l}\text { Values are reported as outcomes of } F \text { tests for joint coefficient significance, with } P \text { values reported in parentheses. Negative outcomes indicate that outcomes have increased less over tim } \\
\text { in areas with the relevant policy bundle than in the areas without the policy bundle. } \\
{ }^{\star} \mathrm{P}<0.10 ;{ }^{\star \star} \mathrm{P}<0.05 ;{ }^{\star \star \star} \mathrm{P}<0.01 \text {. }\end{array}$} \\
\hline
\end{tabular}

\section{RESULTS}

We present results from our village clinic and individual level analyses separately in tables for each type of model (basic, full, and combined). Estimates from specifications with natural log transformed dependent variables can roughly be interpreted as percent changes (or relative changes). Estimates from linear probability models (with dichotomous dependent variables) can be interpreted as percentage point changes (or absolute changes).

Table 2 reports results for village clinics from the basic model. Clinic designation for NCMS reimbursement was associated with a $26 \%$ increase in average weekly patient flow and a $29 \%$ increase in monthly gross income. However, annual net income and share of income from drug sales remained unchanged. Taken together, the gross monthly and net annual income results suggest possible reductions in the provision of specialty services with a high profit margin, as well as possible increases in unfunded clinic responsibilities under NCMS (such as enrolling participants, managing patient reimbursement applications, complying with required facility renovations, and financing mandated clinician training - all of which could have increased costs but not net earnings).

Table 3 shows for results for individuals when the basic model was used. Although participation in NCMS was not associated with a change in the probability of seeking medical care if sick, it was associated with a change in type of facility used when ill. Enrolees in NCMS were $5 \%$ less likely to use township health centres or larger hospitals (or 5\% more likely to use village clinics). The increase in patient flow found at village clinics may therefore be partially due to patients enrolled in the scheme switching from township health centres to village clinics (as well as some unmeasured increase in the frequency of low profit margin service use). Participation in NCMS was also associated with a $19 \%$ reduction in total annual out of pocket medical spending and some reduction in measures of exposure to financial risk. In particular, participation in NCMS was associated with a two percentage point reduction in the likelihood of having net out of pocket health expenditures above the 90th percentile of spending among the uninsured (a 24\% reduction) and a two percentage point reduction in the likelihood of financing medical care through asset sales or borrowing (a 45\% reduction). We investigated the robustness of our results to restricting our sample to households present in both survey waves; these estimates fall within the confidence intervals of our reported results.

Table 4 reports results from the full model for village clinics. Clinic eligibility was positively associated with average weekly patient flow, but no longer significantly so. Instead, a clinic simply being in a village with a NCMS programme was associated with a near doubling of weekly patients (a 55\% increase), implying that the scheme generates large "spillovers" for all local clinics that dominates the effect of individual clinics' eligibility for reimbursement on weekly patient flow. One possible explanation is that NCMS lowers the cost of and thus increases access to medical care at township health centres, therefore increasing the demand for necessary follow-up services and drug refills at local and more accessible village clinics. Estimates for clinic income follow the general pattern found in the basic model and also match the patient flow results of the full model. Clinics in counties with NCMS experienced large increases in gross income (71\%) regardless of clinic eligibility for reimbursement, but no change in net income or share of income from drug sales. Consistent with studies of medical savings accounts (in combination with greater regulation and oversight), ${ }^{1819}$ household account requirements were associated with substantial reductions in clinic weekly patient flow $(-39 \%)$ and nearly significant reductions in clinic gross income. One explanation for this drop in clinic gross income is that individuals with a household account spend account funds more like their own money because the funds can be saved for catastrophic needs or spent in subsequent years (that is, if individuals are restricted to their own household accounts, they spend more cautiously than if they can draw from pooled county funds that cannot be rolled over). Outpatient reimbursement of township health centre services was not associated with any village clinic outcome.

Table 5 presents full model estimates for individual outcomes. As with the basic model, no single policy 
Table $7 \mid$ Impact of the New Rural Cooperative Medical Scheme on individual level outcomes: combined model

\begin{tabular}{|c|c|c|c|c|c|}
\hline & $\begin{array}{l}\text { Probability of seeking } \\
\text { medical care }\end{array}$ & $\begin{array}{l}\text { Probability of seeking } \\
\text { medical care at } \\
\text { township health centre } \\
\text { or larger hospital }\end{array}$ & $\begin{array}{l}\text { Log annual out of pocket } \\
\text { health expenditure }\end{array}$ & $\begin{array}{l}\text { Probability of incurring } \\
\text { out of pocket health } \\
\text { expenditure in the } 90 \text { th } \\
\text { percentile of spending } \\
\text { among uninsured }\end{array}$ & $\begin{array}{l}\text { Probability of financing } \\
\text { healthcare through asset } \\
\text { sales or borrowing }\end{array}$ \\
\hline \multicolumn{6}{|l|}{ Policy bundle A } \\
\hline $\begin{array}{l}\text { Reimbursement for inpatient services at } \\
\text { township health centres and hospitals from the } \\
\text { common fund }\end{array}$ & $-0.01(0.68)$ & $-0.01(0.19)$ & $0.02(0.85)$ & $-0.01(0.50)$ & $-0.03(0.24)$ \\
\hline \multicolumn{6}{|l|}{ Policy bundle B } \\
\hline $\begin{array}{l}\text { Reimbursement for inpatient services at } \\
\text { township health centres and hospitals from the } \\
\text { common fund plus reimbursement for village } \\
\text { clinic services from household accounts }\end{array}$ & $-0.01(0.95)$ & $-0.07(0.21)$ & $-0.21(0.12)$ & $-0.02(0.29)$ & $-0.04^{\star \star \star}(0.00)$ \\
\hline \multicolumn{6}{|l|}{ Policy bundle C } \\
\hline $\begin{array}{l}\text { Reimbursement for inpatient and outpatient } \\
\text { services at township health centres and } \\
\text { hospitals from the common fund plus } \\
\text { reimbursement for village clinic services from } \\
\text { household accounts }\end{array}$ & $0.05(0.26)$ & $-0.08(0.26)$ & $-0.40^{\star \star}(0.03)$ & $-0.03(0.24)$ & $-0.01^{\star \star \star}(0.00)$ \\
\hline
\end{tabular}

feature of NCMS was associated with statistically significant changes in the probability of medical care use when sick or with the choice of where to use services. Outpatient reimbursement was associated with an increase in the probability of using medical care, and clinic reimbursement was associated with a decrease in the probability of using a township health centre or hospital (or an increase in village clinic use), although both these findings fall just below conventional significance levels. The negative relation between participation in NCMS and out of pocket expenditures was no longer significant, but outpatient reimbursement of services received at township health centres was associated with a $19 \%$ decrease in out of pocket medical spending. Household account requirements were also associated with a reduction $(20 \%)$ in out of pocket spending, which together with the other clinic level and individual level results from the full model results implies a reduction in the intensity of service use (if services are used). Finally, reimbursement of village clinic services via the scheme was associated with a three percentage point reduction in the probability of financing medical care through borrowing or asset sales (a 63\% reduction), suggesting that NCMS may provide meaningful protection against financial risk. We again investigated the robustness of our combined model results by restricting our sample to households present in both survey waves; these estimates also fall within the confidence intervals of our reported results.

Table 6 reports combined model results for village clinics, presenting cumulative effects for commonly observed NCMS policy bundles. Estimates and levels of statistical significance for policy bundles A, B, and C are sums across full model estimates for individual policy attributes and corresponding $\mathrm{F}$ tests of their joint significance. Clinic results for policy bundle A in the combined model generally corresponded to those of the basic model. The results for policy bundle B were qualitatively similar to the results for policy bundle A across clinic level outcomes, suggesting that reductions in patient flow and gross monthly income associated with household account requirements are dominated by increases associated with inpatient service coverage. Policy bundle $\mathrm{C}$, the most comprehensive of the three policy bundles, was associated with larger gains in patient flow and gross income for village clinics, again perhaps due to spillover effects of coverage at township health centres. Policy bundles B and C were also associated with reductions in drug sales as a share of clinic revenue $(-24 \%$ and $-22 \%$, respectively). No bundle, however, was associated with a significant change in village clinic annual net revenue.

Table 7 shows combined model results for individual level outcomes. No policy bundle was significantly associated with probability of seeking medical care when sick or with changes in types of facilities used. However, policy bundle $\mathrm{C}$ was associated with a statistically significant $40 \%$ reduction in out of pocket medical care spending. Moreover, policy bundles B and $\mathrm{C}$ were associated with a statistically significant decline in the probability of borrowing or selling assets to pay for medical care.

\section{DISCUSSION}

\section{Principal findings}

Our study provides new evidence on the effect of China's NCMS on village clinics and rural households. For individuals, NCMS is not clearly related to the use of medical care, but it may have re-directed patients away from specialised facilities and towards village clinics. Importantly, while other studies have reported mixed results regarding the effect of NCMS on financial risk protection, ${ }^{20}$ we found evidence that the scheme may have reduced outlier out of pocket spending and the need to borrow or sell assets to pay for medical care. 


\section{WHAT IS ALREADY KNOWN ON THIS TOPIC}

Previous studies of the effect of NCMS-a publically funded health insurance programme covering more than 800 million people in rural China-on large health centres have found that the scheme increases use of inpatient services, but has an uncertain effect on use of outpatient services

Studies have also found that the scheme does not decrease individuals' out of pocket expenditure for inpatient care and has limited effect on impoverishment because of medical expenditures

Very little is known about the effects of the scheme on primary care clinics in villages

\section{WHAT THE STUDY ADDS}

This study is the first to use nationally representative data to study the effect of NCMS on village clinics using both provider and rural household data

The scheme reduces individual patients' health expenditures (in particular health expenditures above the 90th percentile of spending among the uninsured) and the need to borrow or sell assets to finance healthcare, but it does not raise the likelihood of seeking care among village residents

The scheme raises service use and gross income for village clinics, but does not raise net revenue

Perhaps more importantly, the results of our clinic level analyses provide new insight into the scheme's effect on primary healthcare in rural villages. Overall, we found that NCMS has increased clinics' weekly patient flow and gross income, but not annual net revenue. Increases in patient flow and gross, but not net, clinic income might reflect desirable reductions in provision of specialised, high profit margin services and rates of drug sales.

Our results also raise important questions about uncompensated burdens (that is, costs that clinics incur administering the programme that are not reimbursed) that the scheme could have shifted to village clinics. On average, the new clinic revenues from increased patient flow seem to be offset by additional costs. However, there are reasons to suspect that NCMS may have imposed broader costs that do not appear on clinic ledgers. Specific new responsibilities for which clinics are not paid include enrolling participants into the programme (a process that is done each year), managing patient reimbursement applications, complying with regulations concerning mandatory facility renovations, and attending mandated clinician training. Village clinics in our sample spent an average of 43 days per year performing scheme mandated activities like these. However, only $3 \%$ of village clinics received any compensation for them. Even when clinicians received compensation, the amounts were often minimal —on average only 52 Yuan (less than $\$ 7.00$ (£4.40; €5.04), a small fraction of total earnings). Many village clinicians participating in our survey reported that they felt the scheme had hurt their overall business. Given renewed interest among China's policy makers in emphasising primary care, future work is needed to examine more closely the effect of NCMS on rural China's primary care facilities and practices.

\section{Comparison with other studies}

A small number of studies have analysed changes in provider level outcomes under $\mathrm{NCMS}^{21}$ and the effect of smaller scale insurance schemes on village clinics. ${ }^{22-24}$ Our study, however, is one of the first to analyse individual policy attributes of the heterogeneous county level programmes, as well as the first to provide an assessment of how NCMS is affecting village clinics.

\section{Strengths and limitations of study}

Our collection of village clinic data nationwide is unique. Given the substantial heterogeneity in the policy attributes of NCMS across counties in Chinawhich is a significant predictor of important outcomes $^{212526}$ - a particularly attractive aspect of our data is the detailed information about the nature of each county's approach to the scheme. This detail allows us to pinpoint precise policy attributes associated with changes in outcomes among village clinics and rural households.

An important limitation of our study is the nonrandom placement of NCMS programmes in villages and the non-random nature of household decisions to participate. ${ }^{16}$ Our results control for a large number of potentially confounding factors, however, and we have also used other statistical approaches to assess their robustness. Repeating all of the paper's analyses using propensity score matching (which finds the best control group match for each treatment group observation using all observed characteristics simultaneously) yields the same pattern of results as our original analyses but with slightly larger magnitudes (see web appendix).

Several important questions remain that are beyond the scope of our study. Firstly, little is known about the net effect of NCMS on population health outcomes (not simply those measured in clinical settings). Secondly, the clinical and economic appropriateness of changes in service use under NCMS has not been assessed. Thirdly, changes in the quality of medical care deserve further attention, both as rural residents shift where they seek services (towards village clinics, for example) and as provider incentives change. China's rural health system continues to be reformed, and ongoing analysis is required to maximise its benefits as it evolves.

\section{Conclusions and policy implications}

Overall, our study finds that China's NCMS has made progress towards achieving its major goals of providing health insurance to 800 million rural citizens and correcting distortions in rural primary care. Perhaps most importantly, the scheme appears to have successfully provided some protection against the impoverishing effects of illness in rural China and to have reduced out of pocket health spending in general. NCMS might have also partly rationalised use of health services, with some increase in use of primary care and concomitant reductions in specialty care and drug use. However, our findings highlight that these gains might not be sustainable if they have also undermined the financial health of rural China's village clinics.

Contributors: All authors contributed significantly to this article. KSB, GM and SR designed the study and participated in the analysis and interpretation of results. KSB, HY, SR, and LZ participated in the collection of data. GM, KSB, SR, and HY participated in manuscript writing and figure creation, and all authors gave final approval for submission. All authors 
had full access to all the data in the study and take responsibility for the integrity of the data and the accuracy of the data analysis. KSB is responsible for overall content as guarantor.

Funding: We acknowledge funding from the following groups: Stanford University's Presidential Fund for Interdisciplinary International Studies; Massachusetts Institute of Technology; the Chinese Academy of Sciences (Science 100 and KSCX2-YW-N-039); and Social Protection in Asia's (SPA) policy research and network building programme, which is funded by the Ford Foundation and the International Development Research Centre and is managed by the Institute for Human Development, New Delhi, India, and the Institute of Development Studies, Brighton, UK. The funding sources did not have a role in the design or conduct of the study; collection, management, analysis, or interpretation of the data; or preparation, review, or approval of the manuscript.

Competing interests: All authors have completed the Unified Competing Interest form at www.icmje.org/coi_disclosure.pdf (available on request from the corresponding author) and declare that: all authors had support from Stanford University's Presidential Fund for Interdisciplinary International Studies, Massachusetts Institute of Technology, the Chinese Academy of Sciences (Science 100 and KSCX2-YW-N-039), and Social Protection in Asia's (SPA) policy research and network building programme; no relationships with companies or organisations that might have an interest in the submitted work in the previous 3 years; and no other relationships or activities that could appear to have influenced the submitted work.

Ethical approval: Ethics approval was not required for this study. Informed consent was not obtained but the presented data are anonymised and risk of identification is low, so patient consent forms were waived for this study.

Data sharing: The technical appendix, statistical code, and data set are available from the corresponding author at ngmiller@stanford.edu.

1 Liu X, Yi Y. The health sector in China: policy and institutional review. A background paper for the World Bank China Rural Health Study. The World Bank, 2004

2 Wagstaff A, Lindelow M, Wang S, Zhang S. Reforming China's rural health system. The World Bank, 2009.

3 The World Bank. Public expenditure and the role of government financing in the Chinese health sector. The World Bank, 2005.

4 The World Bank. Insuring rural China: rising to the challenge. The World Bank, 2005.

5 Hsiao WC. The transformation of health care in rural China. N Engl/ Med 1984:141:932-6

6 Liu Y. Development of the rural health insurance system in China. Health Policy Plan 2004:19:154-65.

7 Liu Y, Rao K, Hsiao WC. Medical expenditure and rural impoverishment in China. J Health Popul Nutr 2003;21:216-22.

8 Hsiao WC. Chinese health care system: lessons for other nations. Soc Sci Med 1995;41:1047-55.
9 Blumenthal D, Hsiao WC. Privatization and its discontents: the evolving Chinese health care system. $N$ Engl J Med 2005;353:1165-70

10 Lindelow M, Wagstaff A. China's health sector: why reform is needed. The World Bank, 2005.

11 Yip W, Eggleston K. Addressing government and market failures with payment incentives: hospital reimbursement reform in Hainan China. Soc Sci Med 2004;58:267-77.

12 The World Bank. Financing health care: issues and options for China. The World Bank, 1997.

13 Yip W, Hsiao WC. The Chinese health system at a crossroads. Health Aff 2008;27:460-8.

14 Hu S, Tang S, Liu Y, Escobar ML, de Ferranti D. Reform of how health care is paid for in China: challenges and opportunities. Lancet 2008;372:1846-53.

15 Department of Rural Health Management, Beijing. New rural cooperative medical scheme in China. Ministry of Health, 2009.

16 World Health Organization. Implementing the new cooperative medical schemes in rapidly changing China: issues and options. WHO, 2004.

17 Rozelle SD. Stagnation without equity: changing patterns of income and inequality in China's post-reform rural economy. China 1996;35:63-96.

18 Yip W, Hsiao WC. Medical savings accounts: lessons from China. Health Aff 1997;16:244-51.

19 Hsiao WC. Behind the ideology and theory: what is the empirical evidence for medical savings accounts? J Health Polit Policy Law 2001;26:733-7.

20 Wagstaff A, Lindelow M. Can insurance increase financial risk? The curious case of health insurance in China. The World Bank, 2005.

21 Wagstaff A, Lindelow M, Gao J, Xu L, Qian J. Extending health insurance to the rural population: an impact evaluation of China's new cooperative medical scheme. J Health Econ 2009;28:1-19.

22 Yip W, Wang H, Liu Y. Determinants of patient choice of medical provider: a case study in rural China. Health Policy Plan 1998;13:311-22.

23 Zhou Z, Gao J, Xue Q, Yang X, Yan J. Effects of rural mutual health care on outpatient service utilization in Chinese village medical institutions: evidence from panel data. Health Econ 2009;18:S129-39.

24 Yip W, Wang H, Hsiao WC. The impact of rural mutual health care on access to care: evaluation of a social experiment in rural China. Working paper, 2008.

25 Brown P, deBrauw A, Du Y. Understanding variation in the design of China's new cooperative medical system. China $Q$ 2009;198:304-29.

26 Brown P, Theoharides C. Health-seeking behavior and hospital choice in China's new cooperative medical system. Health Econ 2009;18:547-64.

Accepted: 4 August 2010 